\title{
Strategies for the Effective Integration of ICT into Social Organization - Organization of Information Processing and the Necessity of Social Informatics
}

\author{
Klaus Fuchs-Kittowski \\ University of Applied Sciences Berlin, (Germany) \\ fuchs-kittowski@t-online.de
}

\begin{abstract}
This paper discusses strategies and concepts of information and communication-support for knowledge-intensive work processes. The necessity of social informatics or organizational informatics according to Rob Kling results from the complementarity of formal (syntactic), product oriented and informal (semantic), process oriented, technical, and social view in informatics. The understanding of man/computer communication as a problem of linking syntactic and semantic information processing, led to the idea of information centers. The importance of social (organizational) informatics is illustrated in connection with the development of modern information and communication technology; new forms of communication to support international collective research; computer supported knowledge work, as a problem of linking syntactic and semantic information processing. The automated information processing, software use, must be organized, before and during knowledge-intensive work processes take place.
\end{abstract}

Keywords: organization of information processing, social oriented informatics, knowledge-intensive work processes, complementarity, syntactic and semantic information processing, computer networks, information centers. 


\section{The Complementarity of technical and social views in Informatics and the Necessity of a social oriented Informatics}

The decisive basic problem that we have to face when directing our attention to the subject 'Human Choice and Computers' and therefore to social and methodological problems of information processing is the relation between computer and Man, automation and its social environment, between the mechanism and living reality. Informatics especially develops due to the necessity of bridging the gap between the technological automation, working in purely syntactic terms (as information transformer) and the creative, active human being (as a social being), enabled to perform information and knowledge generation and to carry out semantic information processing. Because of these decisive differences, the software use has to be organized and the formal operations have to be integrated into the complex work process of Man.

With today's conference, we want to remember and honor Rob Kling. The author immediately remembers the first encounter with him. Rob Kling was the representative of the USA in the working group 'computers and work' of IFIP TC9. Even if he seldom took part in the meetings, we repeatedly met and talked with each other. I visited him at the University of California Ervine. This visit at his home is for various reasons unforgettably to me. I asked him, what the core of the master course on "computer science and society', introduced by him at the university, was. He answered: "The core of the education in this field is of course organization theories. I don't need to tell you, because you were one of the first, demanding the inclusion of organization theories in information systems design." But our IFIP/TC9 Working group 1 conference in Berlin on 'Information system, Work and Organization design', had not taken place yet [1]. With this remark, he could have hardly referred to our national conferences on 'organization of the information processing' at Humboldt University. However, he could very well have referred to the IFIP/IFAC Conference on 'Socio-technical Aspects of Computerized Automation' (SOTAC) in Budapest, 1979 [2], on discussions in the TC9 (unpublished contributions). He referred to the idea of 'information centers' as an organizational form for the realization of indirect man computer communication, as we had discussed on an IIASA workshop on Data Communications". [3] Like me, he saw this as a proof for the necessity to develop orgware ${ }^{1}$ [4] next to hard- and software. One must develop a new discipline in or with computer science, an organization computer science. Further we discussed the necessity of a social oriented computer science because of the complementarity of formal (syntactic), product-orientated and informal (semantic), process-oriented, technical and social views in informatics. The computer scientist must primarily recognize that this complementarity goes right through the center of the discipline computer science itself. Software must be formally correct and at the same time as a tool adequate for the work process. This 
complementarity of correctness and task adequacy was the inside, which made the paradigm change in software engineering necessary and led to a social orientation of informatics.

During our 'IV colloquium for the organization of the information processing' Christiane Floyd for the first time spoke about the necessity of a paradigm change in the computer science or software technology. She writes: "My topic was: , essential features of a paradigm change in software technology' a precursor to my English paper to which I dared me at that time for the first time" [5].

The emphasis on qualification and users' participation as a source of democratic participation at work and at the processes of change taking place was only one aspect of the problem. The other one was the attention of the abilities and skills as well as the participation in the system design and software development process as a creative process of learning and communication. They then worked this out especially in the STEPmethodology of Christiane Floyd and her coworkers [6], [7], [8].

With reference to the work of Rob Kling, organization informatics developed further in the department of Informatics of the University of Hamburg by Arno Rolf [9] and his coworkers. The development of software and design of complex information systems must occur in a structural coupling with a social organization to integrate complex information systems into the social context. Based on it, Bernd Pape [10] points out that we must organize software use and information processing. In this contribution, we especially want to show that we must organize software also during its use, particularly at problem solution processes, as it is characteristic for knowledge intensive work processes and scientific work. Information centers (or other organizational forms) could be helpful by this necessary organization of software use.

The support of knowledge-intensive work processes and of knowledge management in knowledge-intensive organizations by modern information and communication technologies has become an important topic in informatics. The vision is as follows: ICT-support of cooperation, of knowledge provision, and generation helps to develop creative-learning organizations. If one also takes the local and global social structures of the human society into account, it could be the basis for an information and communication society for all, or even, the basis for the development of the Noosphere in the sense of Teilhard de Chardin and Vladimir I. Vernadsky [11], [12].

\section{New Forms of Communication to Support knowledge Work and International Collective Research}

\subsection{Basic Concepts and the Development of Modern Information and Communication Technology}


The development of a social oriented informatics has proven necessary to integrate computer application systems into the social context and to adapt the computer application systems to the needs of users, though not vice versa. Above all, it is necessary to ensure that we design information systems not according to technical principles alone, but also according to social concepts, values, and objectives.

The question of the relation between the computer and society, and between computer and human choice leads to the discussion of the following issues.

1. Different positions in world outlook regarding the position of Man to his tool

2. Different basic lines resulting from this for the automation of intellectual activities

3. Different directions for the use of computers in various spheres of social life.

As to the position of Man to his tool, the following basic concepts may be distinguished.

1. The concept of the direct and indirect identification of Man and the computer, the position of the most classical, strong AI-researcher (technicism)

2. The concept of a mystic exaggeration of Man's abilities, which is often related to an unjustified criticism of technology (technology pessimism)

3. The concept of a purposeful an effective Man-machine combination, uniting the advantages of human and machine-performed information processing to form an efficient overall system and giving full consideration to the creative abilities of Man.

Obviously, the fist two concepts represent extreme viewpoints resulting from a unilateral visualization of the interaction between Man and computer. We can only overcome this by a dialectical approach to this relationship.

The application of modern information and communication technologies faces us with a multitude of new problems. They not only concern technical and technological problems, but above all, the position of human beings in such complicated technical and technological systems and in the organization, which includes these systems. In this context, explicitly and implicitly extremely varying fundamental attitudes exist that differ in providing a response to this question. That is, we must determine whether we can understand the human being as a disturbing factor, as a relatively imperfect being as compared with automation (so as can be more or less completely replace Man by automation), or whether Man is really seen as the genuine master of these modern technologies. Dependent upon the manner in which we answer this question, we powerfully influence the basic strategies for the utilization of modern information and communication technologies, and research and training programs in informatics. The answer to this question also influences the development of local and global digital networks. 
In the late $1960 \mathrm{~s}$, U.S. scientists created the so-called ARPA-Net that connected military computers and computers of universities with one another. In the early $1980 \mathrm{~s}$, the research institutions used the network to an ever-increasing extent. The U.S. government transferred the network's operation to the National Science Foundation. This also allowed other countries to connect with this network gradually. This became possible, because the ARPA-NET is fundamentally connected to and born of computer science rather than of the military, as Licklider stated in his ARPANET Completion Report [13, p. 96].

At that time, the author took part in further elaborating and developing this approach on intellectual lines, by active participation at the IIASA conference on data communications and further workshops. The title of our paper was 'Man machine communication' - a problem of linking semantic and syntactic information processing [3].

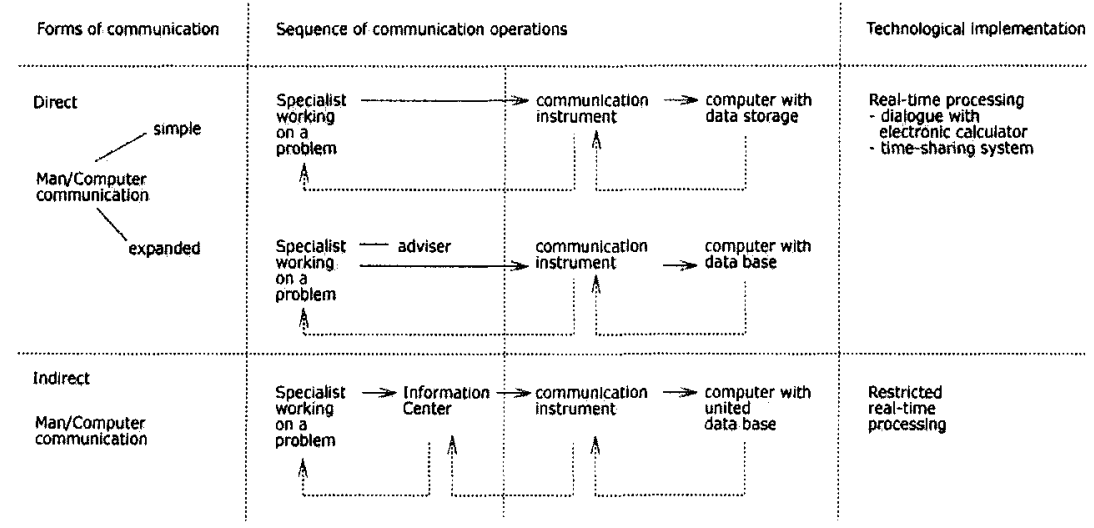

Figure 1: The Need for an Information Center - Different Forms of Man/Computer communication: direct (online) dialog and indirect dialog (via an Information Center) [3]

These ideas were very well received at this conference, but not at home. We always wondered why? Now we know at least part of the answer!

\subsection{Information centers / Thinking center}

In our book Informatics and Automation [7], our thesis, that problem solution processes are not steadily automated, plays a large role. Therefore, different dialogue forms (direct dialog and indirect dialog via an information center) can or must support a combination of man and computer because man/computer communication is a meaningful combination of syntactic (machine) and semantic (human) information processing.

Semantic information processing is the combination of meanings of information to form new meanings. It is typical of man's intellectual information processing that it is concentrated upon the contents. Man 
carries out the structural processes, which are underlying the meaning of words and sentences, unconsciously.

Syntactic information processing is a transformation of the structure of information carriers. Because of specific rules between information carriers and their meanings, we ascribe new meanings to them. The mediation of structural transformations processes the contents of semantic statements.

A reviewer of our book wrote that our strategy of the information center clearly shows how strongly the authors underestimate the forthcoming performances of the artificial intelligence (AI) research. To our satisfaction, we experienced exactly the opposite reaction at the IIASA conference, one of the first public meetings for the development the ARPA-Net. Davis, the developer of the packet switching, jumped up and cried out, "You are right! If the technical net stands once, then the net of the information centers will be the real net."

This different reception of our concept was based on the fact (as we know today) that the net development under J.C.R. Licklider [14] supported the consideration of man and machine having things in common and significant differences. Therefore, we need a sensible man-computer interaction (symbiosis). As a prerequisite for this man-computer symbiosis, Licklider also saw (of course we did not know this at that time) the socalled 'Thinking center' [14]. The leading vision for research on the development of modern digital nets was a technical net by which the people could cooperate internationally. The basic scientific visions developed this for a new way of computer use.

These visions lead once to the understanding of the computer as a medium and on the other hand, to the thought of a combination of the special abilities of the computer with the special abilities of man; J.C.R. Licklider expressed as by his concept of 'Man Computer Symbiosis'.

J.C.R. Licklider wrote "It seems reasonable to envision, for a time 10 or 15 years hence, a 'thinking center' that will incorporate the functions of present-day libraries together with anticipated advances in information storage and retrieval and the symbiotic functions suggested earlier in this paper. The picture readily enlarges itself into a network of such centers. "[14].

We wrote, "By appropriate organizational measures, it is therefore possible to obtain dynamic forms of linking human and machine-operated information processing without having to develop completely new foundations in programming technology. In this respect, the setting up of an information center, by which a special form of man/computer communication is carried out, plays an important role. " [3].

With this statement, we were suddenly, without realizing all its consequences, in the middle of an international struggle for a paradigm change: from an understanding of the computer as a competitor for Man to an understanding of the Computer as an effective part of a Man-ComputerCombination. However, it was not easy to overcome the first position and to introduce the concept of a purposeful and effective Man-ComputerCombination. Therefore, even J.C.R. Licklider had to fight for his idea of a 
'Man Computer Symbiosis', put forward in connection with the development of new forms of communication to support international collective research. H. Dreyfus wrote in his book, What Computers Can't do. The Limits of Artificial Intelligence that at MIT, J.C.R. Licklider wanted to defend him with the words "an interplay of man and machine is presumably most successful". A paper from a scientist at the time working at MIT protested vehemently against it [15, p. 379].

\subsection{Computer aided Knowledge-intensive work processes - a problem of linking semantic and syntactic information processing}

We proceed from the assumption that the scope for setting up new organizational structures has increased decisively with the recent development in modern information and communication technologies, especially with the global electronic network-the Internet. Due to their ability to overcome the restrictions of time and space, network systems promise to enable new types of work, a new culture of knowledge work and scientific work.

With Figure 2, we especially want to stress the point that knowledge as a process and product of a social process is embedded in distributed social activities and that knowledge is generation in cooperation in a work community.

The proposed fundamental difference between syntactic and semantic information processing, the difference between store and memory, the difference between information processing and information generation of forming meanings, is also fundamental here.

Nevertheless, a knowledge-gap characterizes knowledge-intensive work process and even more a scientific work process. It is a problem-solving process. Due to the knowledge-gap, a problem solving process cannot continuously be formalized and thus not generally be automated. In the case of creative aspects of knowledge intensive work processes and scientific work - in the case of cooperative knowledge production the communication-oriented (personal-oriented and social-oriented) approach has therefore to be dominant. Integration with the information-oriented approach (with the formalization and codification strategy) seems to be sensible because the knowledge intensive work process and the scientific work process need both, the provision and the generation of knowledge. The knowledge-intensive and scientific work processes are different mixtures of creative work, routine work and of non-schematic and schematic tasks, which can be formalized. [16], [17, pp 195-210].

If the aim is to increase the cooperation of Man, then from this viewpoint also some various directions complementing each other necessarily are to be discussed in the use of the computer.

1. We can use computers primarily to support the functions of major systems. 
2. We can use computers in support of the functions of the individual human being as the only productive force.

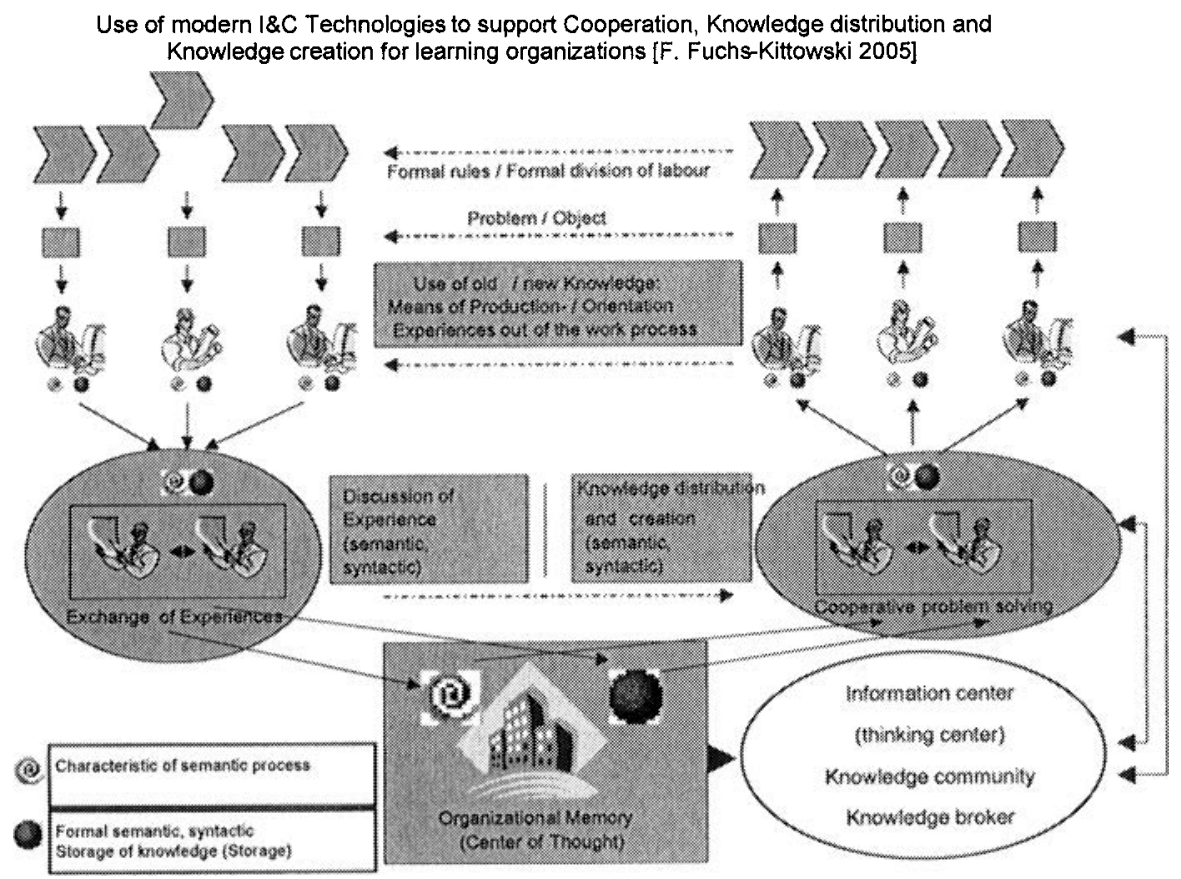

Figure 2: Provision and Generation of Knowledge intensive work processes

The first direction led above all to support managerial and administrative functions and to the immediate process control. In addition, as A. Rolf points out, we can only see certain strategies of knowledge management as a modern version of this direction [18].

The second direction led to computer support in current individual work processes. As the result of the development of interactive systems and, owing to the communication systems, the information processing function of the individual human being, individually or in groups, more and more is assisted in the immediate work operations. Therefore, we could bring information and communication technology closer to the work place. This became the basis for a computer support of knowledge intensive work processes.

We find both directions in the different strategies of the modern knowledge management. In the book Interaktionsorientiertes Wissens Management [16] (Interaction-oriented Knowledge Management) the authors show the necessity of their integration. 
We might suppose that this direction of 'interaction oriented knowledge management' will lead to an essential reinforcement of social organization because of widening the range of abilities proper to the human beings working in knowledge intensive work processes.

The knowledge-intensive work processes requires new cooperative, self-organizing forms for work, organization and learning that support creativity and can be supported by information and communication systems (in particular Tele-cooperation systems).

\subsection{An information center can be useful to organize Software use}

For knowledge workers, people working on problems, we must aim at designing possibilities for ICT applications allowing a very simple transition to a machine-readable formulation of a task. Knowledge workers often require very detailed special knowledge in the field of computer technology and of modeling processes. Above all, non-schematic tasks occur. Nevertheless, the necessity of immediate action and decision is not typical of the creative problem solving process in knowledge work or scientific work. Therefore, it is not necessary to build only direct $\mathrm{man} / \mathrm{computer}$ systems with real time processing. To give aid to the process of working on problems and solving them, especially for management staff of higher levels, and other knowledge workers indirect man/computer communication is by far a more advantageous solution. In indirect communication, a special process of work is switched between the syntactic and the semantic information-processing operations.

This process of work comprises the fact process to be modeled until the formulation of a machine-intelligible data processing task, including cooperation of the user with the modeler (problem analyst) on the semantic level. Therefore, a special organizational component of man/computer communication that is often called an information center (a thinking center) or a knowledge broker carries out the function of mediating.

It is necessary, as F. Fuchs-Kittowski and P. Stahn showed [17], to differentiate between different approaches and strategies of knowledge management: information-oriented approach (with the formalization and codification strategy) and the communication-oriented approach (with the personification and socialization strategy). It also becomes necessary to differentiate between levels of the enterprise organization: a) the individual, b) the group, c) the whole organization, which have to be integrated for an effective knowledge management $[16,17]$. On the different levels of organization (and strategies), we will have a different use of an 'information center' (or 'thinking center'). First, (see Figure 2, organizational memory) we have the orientation towards syntactic storage of knowledge and its retrieval. Here, we will still need the information center (or knowledge broker). On the next level (see Figure 2, cooperative problem solving), an information center in the proposed sense, will not always be necessary. Not that the reductive concept of the direct and indirect identification of Man 
and computer has succeeded! The opposite is true, because the concept of a purposeful an effective Man-computer combination, considering fully the creative abilities of Man, has succeeded, with a strong social orientation. The understanding of knowledge as a social product, the insight, that knowledge generation takes place in social groups, has led to the communication-oriented approach. In these communities of practice, in the process of cooperative problem solving, the function of the 'special organizational form: information center' linking semantic and syntactic information processing can, when needed, also be delegated to specialists in the group. The cooperative problem solving takes place in a group of experts. They might be engaged in this task in such a manner, that not all have to use the information and communication technology themselves, but they now need the knowledge broker: a) to keep updated the knowledge base, b) to organize the experts and c) to gather the results of the individual problem solving processes.

If we look at the information-oriented approach, we see the support of always repeating schematic tasks as typical for the formalizing strategy. Characteristic for the codification's strategy is the support of routine activity. Not formalized routine activities have also creative aspects, because known methods are used in different context. Here an information center in the original proposed sense could be useful, because it becomes necessary to link semantic and syntactic information processing.

If we look at the communication-oriented approach, we see that also the personification strategy deals with the support of routine activities. I $n$ addition, we can introduce an information center, a knowledge broker, linking the syntactic and semantic information processing. Only with the socialization strategy, dealing with the support of creative activities in communities, the main task is the organization of the communication between human beings. This means we can but must not link semantic information processing with the syntactic information processing. The computerized (syntactic) communication system supports the organization of the semantic communication between the experts.

We understand the knowledge intensive work process as a problem solution process. Because of a knowledge gap, we cannot address the problem solution simply by a task solution. Due to the knowledge gap, a problem solution is not a general formalization. We must provide knowledge for the solution of the problem or we must create equipment and conditions to generate the missing knowledge. Here the IKT support needs the organization of software use, it becomes specifically important to select ore construct the prerequisite for the problem solution. The problem aims determine the prerequisites for the problem-solution.

Thus, Frank Fuchs-Kittowski and Peter Stahn [17] differentiate between schematic and non-schematic tasks, between routine and non-routine activities. This leads to a differentiation between an automation of information processing: a) on the basis already existing, b) as a general potential existing and c) yet without existing prerequisites: 
a) Prerequisites already exist and remain constant; we can support alwaysrepeating tasks based on standards.

b) Prerequisites selection, we select the prerequisites for the problem solution from already existing information and operation funds. Therefore, we select or generate them from general prerequisites already created. The prerequisites, required as an information and operation fund, can, however, either already exist or are not yet available.

c) Prerequisite construction, the creation of information and operations funds for the problem solution becomes necessary. In knowledge intensive work process, as problem solving, the aim usually develops and therefore the prerequisites must be created. For a prerequisite construction, the information and operations required for the processes of information processing have to be conceived first, only gradually enlarging the necessary information and operation funds. We have no routine problems here. No knowledge is ready for their solution yet. The prerequisites to make use of the IKT, according to the solution of routine problems, must be created first. This prerequisite construction can, however, be supported by the system of the communication effectively. We can use different forms of organization for the prerequisite construction (see Figure 2, information center, knowledge broker, knowledge community).

\section{Informatics as a socially oriented science}

Automation as an essential element of scientific and technological advance of our time is in no way a purely technological problem to be solved only by knowing and mastering the technological application conditions. This worldwide insight has led to the development of a specific scientific discipline, informatics - and social oriented informatics.

In our article 'Future Expectations to the Designer of modern Information Technologies' [19], we state "If one takes into account, as Rob Kling [20] has worked out in the context of the Curricular debate in the USA, that the predominant part of the computer science graduates gets working for the development and the use of the IKT in social organizations, in the education one must take into account these IKT application areas and their problems correspondingly. An orientation towards the problems of an 'organizational computing', [20] an 'Organisationsinformatik' wasn't, at least in the context of computer science, carried out till now" [19].

One overlooks there that this change of the guidelines (paradigm change) is forced from the technological development, the economic requirements, and the social development. An economically effective and socially justified application of modern information and communication technology requires a social orientation, which is carried at least by the insight that information system design at the same time has to be work and organization design. It definitely would be important, as R. Kling stated, to determine once, which economic damage is caused, how expensive the 
failure is for the society, not to include social - and also information science cognition's in the information system development.

Informatics has especially the task of elaborating some principles for understanding and methods for describing the interrelations between man and the automation, as well as between man and his working environment [21], and of working out viewpoints for judging and forms of computer application, as well as recommendations and criteria for a humanistic system design [22]. Above all it is necessary to ensure that the design of automata-supported information systems in economics, education, the legal system and the health service are not only derived from technological principles but performed according to social ideas of values and goals [23], [24], [25].

To develop an information society for all is a very important technical and social goal. Seen together with the concept of sustainable development this would be a substantial social innovation [26], [27]

Nevertheless, it is not a very deep concept that concerns real social development. We rather think that a further task actually lies before us. The one that must be carried out is really to integrate the potentials of information - and communication technologies in the process of shaping social and individual development, on the basis of a modern scientifically proven social concept and humanistic social visions, as the Noosphere Vision of Pierre Teilhard de Chardin and Vladimir I. Vernadsky [28].

We should do this task in such a way that man is and remains the stating point and aim of the shaping of systems of social organization.

\section{Acknowledgement}

The author thanks Frank Fuchs-Kittowski for many helpful discussions on this topic.

\section{References}

1. P, van den Besselaar, A. Clement, and P. Järvinen, Information system, Work and Organization design, North Holland, Amsterdam, 1991

2. K. Fuchs-Kittowski, U. Schuster, and B. Wenzlaff, Organizational, Technological and Social Problems of Computerization, Computer in Industry (2), 275-285 (1981).

3. K. Fuchs-Kittowski, K. Lemgo, U. Schuster, and B. Wenzlaff, Man / Computer Communication - A Problem of Linking Semantic and Syntactic Information Processing, Workshop on Data Communications (International Institute for Applied Systems Analysis, Laxenburg, 1975), pp. 169-188.

4. Le Programme FAST II (1984-1987) Perspective et évaluation de la science et de la technologie, Synthèse des Résultats, First Draft

5. C. Floyd, Laudatio, in: Stufen zur Informationsgesellschaft - Festschrift zum 65. Geburtstag von Klaus Fuchs-Kittowski, edited by C. Floyd, C. Fuchs, and W. Hofkichner, (Peter Lang Verlag, Frankfurt/Main, 2002). 
6. C. Floyd, Software-Engineering - und dann?, Informatik Sprektrum 17(1), pp. 29-37 (1994).

7. K. Fuchs-Kittowski, H. Kaiser, R. Tschirschwitz, and B. Wenzlaff, Informatik und Automatisierung - Theorie und Praxis der Struktur und Organisation der Informationsverarbeitung, Akademie Verlag, Berlin, 1976.

8. K. Fuchs-Kittowski, Informatik und Computer - Organisationstheorie als ein konzeptioneller, theoretisch-methodologischer Bezugsrahmen für die effektive Integration der modernen Informationstechnologien in soziale Organisation, in: $I V$. Wissenschaftliche Kolloquium zur Organisation der Informationsverarbeitung, Humboldt Universität, Berlin, 1983.

9. A. Rolf, Grundlagen der Organisations- und Wirtschaftsinformatik, Springer Verlag, Berlin et al., 1998.

10. B. Pape, Organisation der Softwarenutzung - Theorienbildung und Fallstudien $z u$ Softwareeinführung und Softwarebetreuung, Logos Verlag, Berlin, 2005.

11. T. de Chardin, Der Mensch im Kosmos, Union Verlag, Berlin, 1959; (C.H. Beck, München, 1959).

12. V. Vernadsky, The biosphere and the noosphere, American Scientist 33 (1), 1-12 (1945).

13. M. Hauben, and R. Hauben, Netizens - On the History and the Impact of Usenet and the Internet, IEEE Computer Society Press, Los Alamitos, 1997.

14. J.C.R. Licklider, Man-Computer Symbiosis, IRE Transactions on Human Factors in Electronics, (1) 4-111 (1960); J.C.R. Licklider, Man-Computer Symbiosis, 1990, http://memex.org/licklider.pdf (March 31, 2006).

15. H. Dreyfus, Die Grenzen künstlicher Intelligenz - Was Computer nicht können, (Athenäum, Königstein, 1985) (What Computers can't do - The limits of Artificial Intelligence, New York)

16. F. Fuchs-Kittowski, and W. Prinz, Interaktionsorientiertes Wissensmanagement (Peter Lang Verlag, Frankfurt/M., 2005).

17. F. Fuchs-Kittowski, and P. Stahn, Kooperative Wissensarbeit in wissensintensiven Dienstleistungen - IT-Unterstützung mit der WiKoAnwendung aus Anwendersicht, in: Entwicklung innovativer DienstleistungenWissen, Kreativität, Lernen, edited by T. Schlegel, and D. Spath, Dieter Fraunhofer IRB Verlag, Stuttgart, 2005, pp. 195-210.

18. A. Rolf, Informatiksysteme in Organisationen und globalen Gesellschaften, IMG 4-Skript, WS 2004/05, 2004, Fachbereich Informatik, Universität Hamburg

19. K. Fuchs-Kittowski, and H. Juncker, Zukünftige Erwartungen an den Gestalter moderner Informationstechnologien, in: InfoTech - 5 (4) 42-50 (1993).

20. R. Kling, Organizational Analysis in Computer Science, The Information Society 9 (2) (1993).

21. K. Fuchs-Kittowski, and F. Fuchs-Kittowski, Quality of working life knowledge-intensive work processes and creative learning organizations Information processing paradigm versus self-organization theory, in: Human Choice and Computers - Issues of Choice and Quality of Life in the Information Society, edited by K. Brunnstein, and J. Berleur, Kluwer Academic Publishers, Boston, 2002, pp. 265-274.

22. M. Nurminen, People or Computers - Three Ways of Looking at Information Systems, Chartwell-Bratt, Lund, 1988.

23. J. Berleur et al., Risks and Vulnerability in an Information and Artificial Society, Proceedings of the IFIP 12th World Computer Congress, Madrid, Spain, Volume II, 1992, pp. 309-310.

24. K. Brunnstein, Perspectives of the Vulnerability of IT-based Society, in Proceedings of IFIP 12th World Computer Congress, Madrid, Spain, Volume II, 1992, pp. 588-592. 
25. K. Fuchs-Kittowski, H.A. Rosenthal, and A. Rosenthal, Die Entschlüsselung des Humangenoms - ambivalente Auswirkungen auf Gesellschaft und Wissenschaft. EWE - Erwägen, Wissen, Ethik 16 (2) (2005) pp. 149 -- 162 u. 219- 234

26. A. Rolf, and A. Moeller, Sustainable Development - Gestaltungsaufgabe der Informatik. Informatikspektrum 19 (4) 206-213 (1996).

27. K. Fuchs-Kittowski, J.L. Heinrich and A. Rolf, Information entsteht in Organisationen - in kreativ lernenden Unternehmen - wissenschaftstheoretische und methodologische Konsequenzen für die Wirtschaftsinformatik, in: Wirtschaftsinformatik und Wissenschaftstheorie, edited by Becker, König, Schütte, Wend, Zelewski (Gabler Verlag, Wiesbaden, 1999).

28. K. Fuchs-Kittowski, and P. Krüger, The Noosphere Vision of Pierre Teilhard de Chardin and Vladimir I. Vernadsky in the Perspective of Information and of World-Wide Communication, in: The Quest for a Unified Theory of Information, World Futures General Evolution Studies Vol. 13, edited by W. Hofkirchner, Gordon and Breach Publishers, Amsterdam, 1999.

1 G. Dobrow and I had introduce the term orgware in the International Institute of Applied Systems Analysis (IIASA). From there the term orgware was taken and advocated in the FAST-Report (FAST : Forecasting and Assessment in Science and Technologie [4]). 